\title{
Tensions grow over health research proposals
}

London. A fierce struggle is developing between Britain's teaching hospitals, its medical research establishment and the Conservative government over the control of funds allocated for the support of research by the National Health Service (NHS).

At stake is the question of how healthrelated research should be funded in a political environment where the government is demanding market-style thinking in all NHS activities. Many research-based institutions that have relied on the NHS for support in the past are worried about the consequences for their own survival.

Medical schools are, in particular, concerned about the conclusions of an unpublished report, commissioned last year by the Department of Health and delivered to the government at the end of April. This is expected to suggest that the NHS funds they receive to cover the indirect costs of research should be allocated separately from those provided for teaching, and subjected to far greater scrutiny than at present.

Both teaching and research funds are provided currently through the so-called Special Increments for Teaching and Research (SIFTR), which provides up to 20 per cent of the funding of teaching hospitals through regional health authorities.

SIFTR money is distributed according to a formula based primarily on clinical student numbers. "The system works, and it works well," says Peter Richards of St Mary's Hospital Medical School in London, chairman of the council of the Deans of UK Medical Schools.

Reforms that made it more difficult to obtain NHS support for research could mean that some university teaching hospitals "could go broke", he warns. Similarly, redirecting research funds to other institutions considered more 'productive' by the government would amount to little more than "robbing Peter to pay Paul".

Both proposals, however, are believed to figure in the report on NHS research prepared by a task force chaired by Anthony Culyer, professor of economics and provice-chancellor of the University of York.

At the same time, the government itself is believed to be unhappy about another conclusion of the report, namely that bodies such as hospital trusts, which it wants to turn into the main decision-makers for allocating NHS funds as the 'purchasers' of health care, are not well placed to make decisions about what research they should be supporting.

Publication of the detailed proposals made by Culyer on how to separate out the research element of SIFTR funding, and how to organize the 'top-slicing' of money allocated to local bodies for health service research, is still awaiting a decision by the health minister, Brian Mawhinney.

But, speaking at a meeting in London organized by the British Postgraduate Medical Federation, Culyer said he was able to reveal some of the basic principles the drafting group had agreed on, and which underpin its main conclusions.

On the current arrangement for funding teaching hospitals, for example, Culyer said that most of the 200 individuals and institutions who provided evidence to the task force "wanted to see the teaching and research components of SIFTR separated".

Culyer added that it was "widely felt" that the research infrastructure in general practice and health care "generally needed core funding based on university departments and networks of research-oriented community-based practice".

Similarly, there were a number of reasons, he said, why giving health-care purchasers responsibility for commissioning research on top of all their other responsibilities "seemed to us not only completely unrealistic under present circumstances, but probably inappropriate".

He listed four reasons for this conclusion: that the fruits of research and development (R\&D) are a 'public good'; that the various skills required to commission research properly are 'very scarce'; that giving a single organization responsibility for both health care and R\&D purchasing "would pose a terrible dilemma for local decision makers"; and that local purchasers were rarely on international research networks.

Health-care purchasers needed to be given a significant voice in decisions about the allocation of R\&D resources, said Culyer, "but without wrecking the system of rocks and whirlpools I have just described".

Such a conclusion, if it survives in the published version of Culyer's report, is likely to be welcomed by the Medical Research Council. Many MRC scientists have recently been complaining that the reorganization of the health service - and in particular the greater discretionary powers being given to local purchasers - threatens to undermine Britain's traditional strengths in clinical research.

But it is a direct challenge to the thinking of government ministers who have been arguing in favour of raising these powers to a maximum. How far they are prepared to retreat from this position to meet the requirements of research is now being hotly debated in Whitehall.

David Dickson 